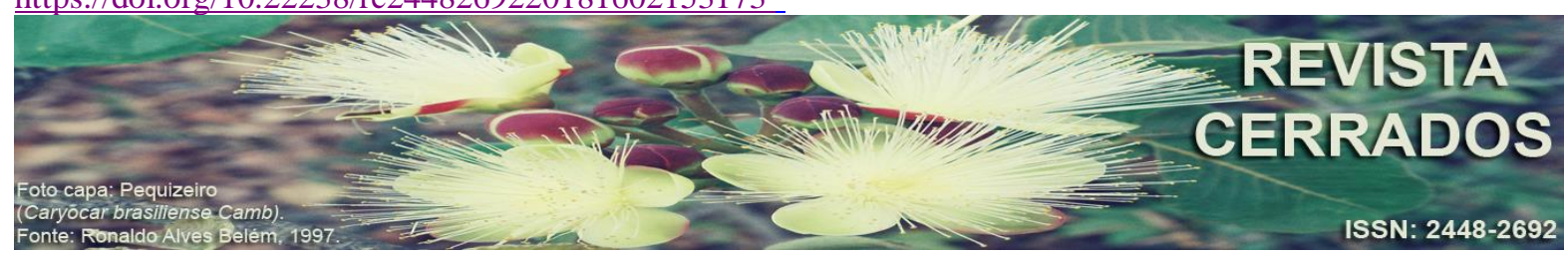

\title{
ANÁLISE ESPACIAL DAS UNIDADES DE PAISAGEM DA RESERVA EXTRATIVISTA MARINHA MOCAPAJUBA, ZONA COSTEIRA DO NORDESTE PARAENSE
}

\author{
SPATIAL ANALYSIS OF THE LANDSCAPE UNITS OF THE \\ MOCAPAJUBA MARINE EXTRACTIVE RESERVE, COASTAL ZONE \\ OF NORTHEAST OF THE PARÁ STATE
}

\author{
ANÁLISIS ESPACIAL DE LAS UNIDADES DE PAISAJE DE LA \\ RESERVA EXTRATIVISTA MARINA MOCAPAJUBA, ZONA \\ COSTERA DEL NORDESTE PARAENSE
}

\author{
Jones Remo Barbosa Vale \\ Universidade Federal Rural da Amazônia - UFRA \\ E-mail: <jonesremo@ hotmail.com>. \\ Tabilla Verena da Silva Leite \\ Universidade Federal Rural da Amazônia - UFRA \\ E-mail: <tabillaverena@hotmail.com>. \\ Elton Luis Silva da Silva \\ Universidade Federal Rural da Amazônia - UFRA \\ E-mail: <eltonsylver@gmail.com>. \\ Jefferson Ferreira dos Santos \\ Universidade Federal Rural da Amazônia - UFRA \\ E-mail: <jefhersonds@gmail.com>.
}

\section{RESUMO}

A Reserva Extrativista Marinha Mocapajuba localiza-se no município de São Caetano de Odivelas, zona costeira do nordeste paraense. É uma unidade que se enquadra na categoria de uso sustentável, constitui-se em um espaço territorial destinado à exploração autossustentável e a conservação dos recursos naturais renováveis. $O$ trabalho tem por objetivo fazer uma análise espacial das unidades de paisagem da Resex Marinha Mocapajuba para fornecer subsídios para o planejamento ambiental e ordenamento territorial da unidade. Com base nos pressupostos teórico-metodológico geossistêmico e utilizando dados em formatos vetoriais e matriciais que foram processados em ambiente de Sistema de Informação Geográfica, fez-se o cruzamento das informações e obteve-se 7 unidades de paisagem, são elas: Geossistema da

Licenciada sob Creative Commons (cc) $1 \mathrm{EY}-\mathrm{Ha}-\mathrm{HL}$
Revista Cerrados, Departamento de Geociências e Programa de Pós-Graduação em Geografia (UNIMONTES) 
VALE, J. R. B.; LEITE, T. V. S.; SILVA, E. L. S.; SANTOS, J. F.

Análise espacial das unidades de paisagem da reserva extrativista Marinha Mocapajuba, Zona Costeira do

Nordeste Paraense

Planície Costeira com Campos; Geossistema da Planície Costeira com Manguezal; Geossistema da Planície Costeira com Ocupação Humana; Geossistema da Planície Costeira com Restinga; Geossistema dos Tabuleiros com Campos; Geossistema dos Tabuleiros com Capoeira e Solo Exposto; Geossistema dos Tabuleiros com Vegetação Secundária. Assim, a delimitação das unidades de paisagem mostrou-se um importante instrumento para subsidiar a elaboração de um plano de manejo que é um dos principais instrumentos de gestão e a unidade de estudo ainda não possui o seu.

Palavras-Chave: Unidades de Conservação. Unidades de Paisagem. Zona Costeira.

\begin{abstract}
The Mocapajuba Marine Extractive Reserve is located in the municipality of São Caetano de Odivelas, Coastal Zone of Northeast of the Pará State. It is a unit that falls within the category of sustainable use, constitutes a territorial space destined to the self-sustainable exploitation and the conservation of the renewable natural resources. The work aims to make a spatial analysis of the landscape units of Resex Marinha Mocapajuba to provide subsidies for the environmental planning and territorial planning of the unit. Based on the theoreticalmethodological assumptions geosistemic and using data in vector and matrix formats that were processed in a Geographic Information System environment, the information was crossreferenced and 7 landscape units were obtained, they are: Geosystems of the Coastal Plain with Fields; Geosystem of the Coastal Plain with Mangrove; Geosystems of the Coastal Plain with Human Occupation; Geology of the Coastal Plain with Restinga; Geosystem of the Trays with Fields; Geosystem of Trays with Capoeira and Exposed Soil; Geosystem of Tracks with Secondary Vegetation. Thus, the delimitation of the landscape units has proved to be an important instrument to subsidize the elaboration of a management plan that is one of the main management instruments and the unit of study does not yet have its own.
\end{abstract}

Keywords: Conservation Units. Landscape Units. Coastal Zone.

\title{
RESUMEN
}

La Reserva Extractiva Marina Mocapajuba se ubica en el municipio de São Caetano de Odivelas, zona costera del nordeste paraense. Es una unidad que se enmarca en la categoría de uso sostenible, se constituye en un espacio territorial destinado a la explotación autosostenible y la conservación de los recursos naturales renovables. El trabajo tiene por objetivo hacer un análisis espacial de las unidades de paisaje de la Resex Marinha Mocapajuba para proporcionar subsidios para la planificación ambiental y ordenación territorial de la unidad. Con base en los supuestos teórico-metodológico geosistémico y utilizando datos en formatos vectoriales y matriciales que fueron procesados en ambiente de Sistema de Información Geográfica, se hizo el cruce de las informaciones y se obtuvieron 7 unidades de paisaje, son ellas: Geosistema de la Llanura Costera con Campos; Geosistema de la Llanura Costera con Manguezal; Geosistema de la Llanura Costera con Ocupación Humana; Geosistema de la Llanura Costera con Restinga; Geosistema de los Tableros con Campos; Geosistema de los tableros con capoeira y suelo expuesto; Geosistema de los Tableros con Vegetación Secundaria. Así, la delimitación de las unidades de paisaje se mostró un importante 
VALE, J. R. B.; LEITE, T. V. S.; SILVA, E. L. S.; SANTOS, J. F.

Análise espacial das unidades de paisagem da reserva extrativista Marinha Mocapajuba, Zona Costeira do Nordeste Paraense

instrumento para subsidiar la elaboración de un plan de manejo que es uno de los principales instrumentos de gestión y la unidad de estudio aún no posee el suyo.

Palabras Claves: Unidades de Conservación. Unidades de Paisaje. Zona Costera.

\section{INTRODUÇÃO}

As questões ambientais têm ocupado um grande espaço nas discussões científicas da contemporaneidade, sobretudo, por conta do homem na busca pelo desenvolvimento econômico e uso descomedido dos recursos naturais, modelo de desenvolvimento descrito por Trigueiro (2005) como "ecologicamente predatório, socialmente perverso e politicamente injusto". Embora o desenvolvimento econômico com base na utilização dos recursos naturais proporcione o bem-estar social e econômico para uma parcela da sociedade, os objetivos da conservação se contrapõem a esse modelo (COSTA, 2000). Sendo assim, amplia-se o debate acerca da proteção e conservação de áreas visando à manutenção dos ecossistemas.

Segundo Medeiros (2006) as Áreas Protegidas, de forma geral, são espaços territorialmente demarcados, cuja principal função é a conservação e/ou a preservação de recursos, naturais e/ou culturais, a elas associados. No Brasil, elas são instituídas a partir da publicação de leis ou decretos de criação. Atualmente, no território brasileiro são reconhecidas as seguintes áreas protegidas: Área de Preservação Permanente (APP); Reserva Legal; Terras Indígenas (TI), Territórios Quilombolas e Unidades de Conservação (UC's). Especificamente, por conta de demandas locais e internacionais criaram-se várias UC's no Brasil, ao longo do século XX, e cada vez mais vem se ampliando áreas que visam à conservação de diversos espaços em diferentes ecossistemas brasileiros.

Em 2000, com o objetivo de ordenar as UC's brasileiras e atender os designíos da Política Nacional de Meio Ambiente (PNMA), foi criado o Sistema Nacional de Unidades de Conservação da Natureza (SNUC), por meio da Lei Federal nº 9.985/2000 (BRASIL, 2000). Esse sistema é formado pelo conjunto das UC's federais, estaduais e municipais existentes no Brasil. A gestão destes territórios tão importantes para conservação dos recursos naturais está dividida em Unidades de Conservação de Proteção Integral e Unidades de Conservação de Uso Sustentável (BARROS, 2017).

A Reserva Extrativista (Resex) é um tipo de unidade de conservação que se enquadra na categoria de uso sustentável, constitui-se em um espaço territorial destinado à 
VALE, J. R. B.; LEITE, T. V. S.; SILVA, E. L. S.; SANTOS, J. F.

Análise espacial das unidades de paisagem da reserva extrativista Marinha Mocapajuba, Zona Costeira do Nordeste Paraense

exploração autossustentável e a conservação dos recursos naturais renováveis, por populações tradicionais. No processo de gestão da Resex existe um contato frequente entre populações tradicionais e técnicos do órgão gestor. Estes manifestam diferentes graus de ativismo e convive com interesses envolvendo o bem-estar socioeconômico das comunidades, a preservação de suas culturas e do meio ambiente. Nessa convivência, transitam entre diversas visões ambientalistas e relações de poder entre conhecimento científico e tradicional (MENEZES et al., 2011).

No ano de 2014, o Governo Federal, criou no litoral do nordeste paraense três reservas extrativistas, dentre elas a Resex Marinha Mocapajuba, criada por meio do Decreto de 10 de outubro de 2014, visando garantir a conservação da biodiversidade dos ecossistemas de manguezais, restingas, dunas, várzeas, campos alagados, rios, estuários e ilhas, além de assegurar o uso sustentável dos recursos naturais e proteger os meios de vida e a cultura das comunidades tradicionais extrativistas da região (BRASIL, 2014).

Após a criação de uma UC deve ser elaborado o plano de manejo que é um documento técnico que regula a utilização dos recursos naturais da unidade, tendo em vista suas características regionais e locais (BRASIL, 2000). Bensusan (2006) destaca que a maior razão para justificar a necessidade de manejar os ecossistemas a serem conservados nas áreas protegidas é a dimensão do impacto humano e suas consequências para a nossa espécie. Para mitigar os efeitos de fenômenos como conversão de áreas naturais, espécies invasoras, ampliação da atuação de patógenos, poluição química e industrial, o manejo é ferramenta fundamental.

Uma das ferramentas mais importantes do plano de manejo é o zoneamento da unidade, que a organiza espacialmente em zonas sob diferentes graus de proteção e regras de uso (BRASIL, 2018). Dentre os vários tipos de zoneamento, o que mais condiz com o de UC é o Zoneamento Ambiental, que se caracteriza por atuar na identificação das características ambientais (potencialidades, vocações, limites e fragilidades), visando sempre ao menor impacto possível na área, contribuindo para o desenvolvimento sustentável e também para o ordenamento territorial (FOLETO; ZIANI, 2013).

Para se elaborar um plano de manejo ou qualquer instrumento de ordenamento e gestão da UC é necessário conhecer as características do meio físico, biótico e antrópico. A análise integrada da paisagem é influenciada pela Ecologia da Paisagem que numa 
VALE, J. R. B.; LEITE, T. V. S.; SILVA, E. L. S.; SANTOS, J. F.

Análise espacial das unidades de paisagem da reserva extrativista Marinha Mocapajuba, Zona Costeira do Nordeste Paraense

perspectiva sistêmica do meio ambiente torna-se uma importante estratégia metodológica para as UC's, principalmente, por permitir sua representação em uma escala que proporciona a conversão em unidades de paisagem e em documentos cartográficos (TRICART, 1982; MARQUES NETO, 2008).

Ross (1992) coloca que as unidades de paisagem se individualizam pelo relevo, clima, cobertura vegetal, solos ou até mesmo pelo arranjo estrutural e o tipo de litologia ou exclusivamente por um desses elementos. Deste modo, Monteiro (1987) define as unidades como “(...) as correlações básicas estabelecidas entre os elementos do quadro natural (...) dinamizado por aqueles de ocupação antrópica, com suas derivações sucessivas, sugerem padrões de organização espacial que induzem a definição de conjuntos ambientais".

A delimitação de unidades de paisagem apresenta grande complexidade, pois a interação entre os diversos atributos do sistema natural e do sistema antrópico permite tanto a identificação dos atributos responsáveis pela dinâmica da paisagem quanto as principais fragilidades ambientais de cada unidade, elemento essencial no planejamento e gestão do território (AMORIM; OLIVEIRA, 2008).

Sendo assim, os pressupostos teórico-metodológicos da abordagem sistêmica e o uso de geotecnologias, principalmente, com o Sistema de Informação Geográfica (SIG) vem contribuindo para a sistematização de dados, sendo suporte para dinamizar análises espaciais (CLEMENTE; SANTOS, 2017), proporcionando a elaboração de mapas temáticos e diagnósticos que possam subsidiar a gestão das UC's. Desta forma, o trabalho tem como objetivo fazer uma análise espacial das unidades de paisagem da Reserva Extrativista Marinha Mocapajuba para fornecer subsídios para o planejamento ambiental e ordenamento territorial da unidade.

\section{METODOLOGIA}

\section{Área de Estudo}

A Reserva Extrativista Marinha de Mocapajuba localiza-se no município de São Caetano de Odivelas, zona costeira do nordeste paraense (Figura 1). Limita-se ao norte com o oceano atlântico; a leste com o município de Curuçá; a oeste com o município de Vigia; e ao 
VALE, J. R. B.; LEITE, T. V. S.; SILVA, E. L. S.; SANTOS, J. F.

Análise espacial das unidades de paisagem da reserva extrativista Marinha Mocapajuba, Zona Costeira do Nordeste Paraense

sul com São João da Ponta. Possui uma área de aproximadamente 21.029 de hectares. Essa unidade é federal, sendo o Instituto Chico Mendes de Conservação da Biodiversidade/ Ministério do Meio Ambiente (ICMBio) o órgão responsável pela gestão.

Figura 1. Localização geográfica da área de estudo

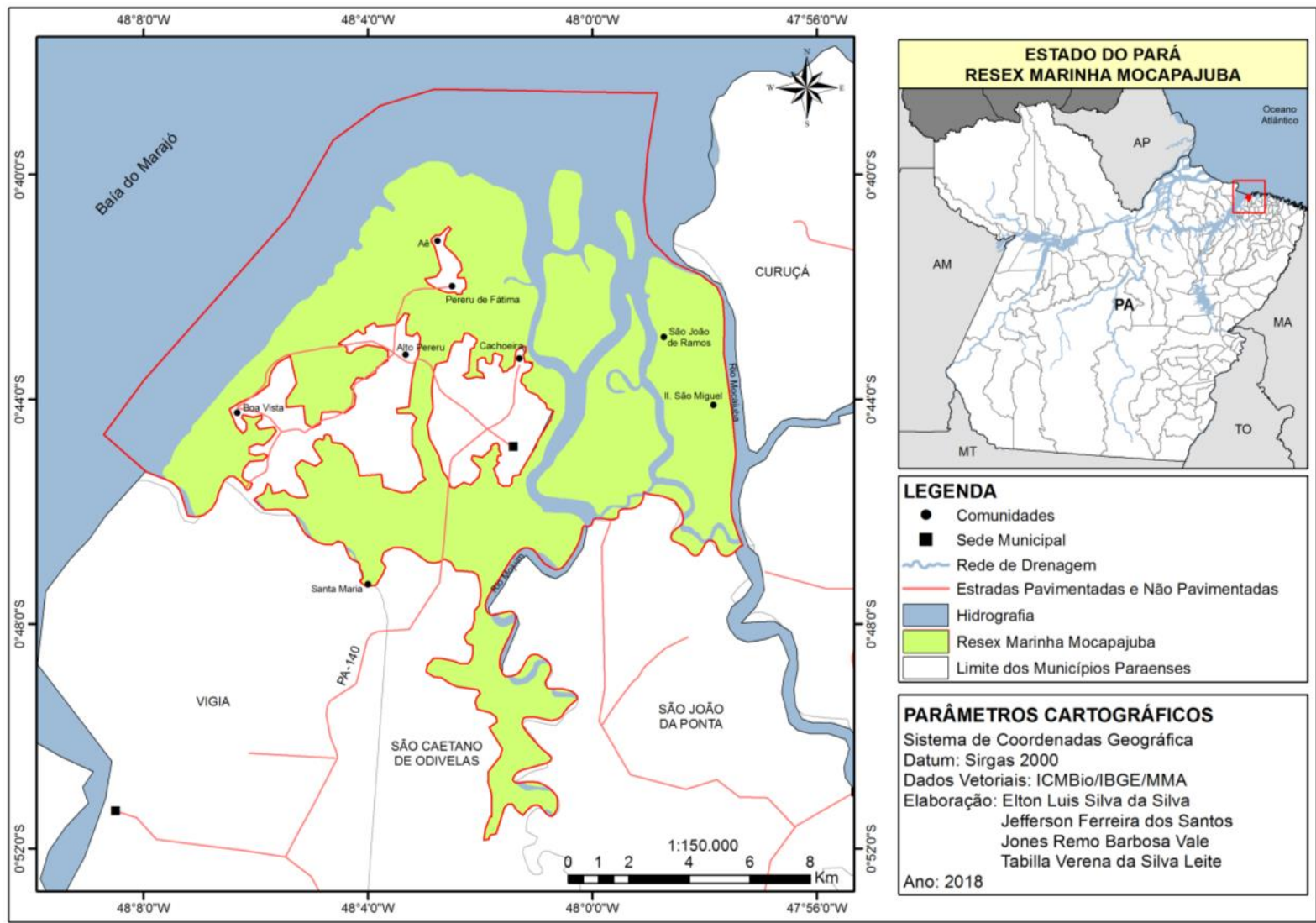

Fonte: Elaborado pelos autores, 2018.

A Resex Marinha Mocapajuba é uma unidade de uso sustentável que tem como propósito garantir a conservação da biodiversidade dos ecossistemas e assegurar o uso racional dos recursos naturais. Sendo assim, na área da unidade é praticada a pesca artesanal, assim como a retirada de caranguejos, sendo esta última à principal atividade econômica do município de São Caetano de Odivelas. Além disso, em algumas comunidades próximas aos rios da região se prática a aquicultura, principalmente de ostras. Na unidade o que mais tem preocupado são as pressões antrópicas sob o principal ecossistema da região, o manguezal, presente em boa parte da unidade. 
VALE, J. R. B.; LEITE, T. V. S.; SILVA, E. L. S.; SANTOS, J. F.

Análise espacial das unidades de paisagem da reserva extrativista Marinha Mocapajuba, Zona Costeira do Nordeste Paraense

\section{Materiais e Métodos}

Inicialmente extraiu-se os limites territoriais da unidade do arquivo vetorial de unidades de conservação disponibilizado pelo ICMBio. Para fazer a caracterização ambiental da unidade foram utilizados dados em formato vetorial e matricial de: pedologia da Empresa Brasileira de Pesquisa Agropecuária (Embrapa); geologia e geomorfologia do Instituto Brasileiro de Geografia e Estatística (IBGE); precipitação e temperatura do Instituto Nacional de Meteorologia (INMET); declividade e hidrografia extraídos do Modelo Digital do Terreno (MDT) derivado do mosaico de imagens SRTM (SA-22-X-A e SA-22-V-B) disponibilizadas pelo Instituto Nacional de Pesquisas Espaciais (INPE).

A classificação de uso e cobertura da Terra da área de estudo foi realizada em uma imagem de satélite do Landsat-8/OLI-TIRS do ano de 2017 que está disponibilizada no acervo da memória da plataforma Google Earth Engine (GEE). O processamento foi executado pelo Code Editor do GEE a partir de script desenvolvido em linguagem de programação JavaScript, com aplicação do algoritmo Random Forest, que segundo Breiman (2001) é um classificador formado por uma coleção de árvores de classificação, cada qual construída a partir de uma reamostra aleatória do conjunto de treinamento original, onde a classificação de um vetor de características x e feita por votação, submetendo-se o vetor as árvores da floresta e atribuindo-se a x a classe mais votada.

Neste mesmo script foram aplicados dois índices espectrais, o Índice de Vegetação por Diferença Normalizada (NDVI) que é um indicador das alterações na cobertura vegetal, e o Modified Normalized Difference Water Index (MNDWI) que segundo $\mathrm{Xu}$ (2006) visa suprimir o ruído proveniente das características das áreas construídas, desta forma, considera que um corpo hídrico apresenta maior absorção na banda do infravermelho. Também aplicou-se a banda adicional do Landsat 8 que mensura a qualidade do pixel, Band Quality Assessment (BQA). As características das classes mapeadas estão dispostas no Quadro 1. 
VALE, J. R. B.; LEITE, T. V. S.; SILVA, E. L. S.; SANTOS, J. F.

Análise espacial das unidades de paisagem da reserva extrativista Marinha Mocapajuba, Zona Costeira do Nordeste Paraense

Quadro 1. Características das classes de uso e cobertura da Terra

\begin{tabular}{|c|c|}
\hline CLASSE & DESCRIÇÃO \\
\hline Campos & $\begin{array}{l}\text { Áreas que se constitui na planície costeira, periodicamente alagável. A } \\
\text { vegetação é predominante de gramíneas e outros tipos de herbáceas. }\end{array}$ \\
\hline Comunidade & Áreas ocupadas por populações tradicionais. \\
\hline Hidrografia & Águas superficiais formadoras de espelhos d’água, como rios e igarapés. \\
\hline Manguezal & $\begin{array}{l}\text { Área formada pelos sedimentos lamosos oriundos de depósitos holocênicos, } \\
\text { se constitui da planície lamosa costeira. No ambiente, há o predomínio de } \\
\text { vegetação hálofila, com espécies do tipo Laguncularia racemosa, Rhizophora } \\
\text { mangle e/ou Avicenia germinans. }\end{array}$ \\
\hline Restinga & $\begin{array}{l}\text { Área representada por sedimentos arenosos oriundos de depósitos holocênicos } \\
\text { atuais, se constitui a planície arenosa. A vegetação tem pobreza de nutrientes } \\
\text { e água nos solos arenosos, salinidade, mobilidade das dunas e calor. }\end{array}$ \\
\hline Vegetação Secundária & $\begin{array}{l}\text { Áreas que, após a supressão total da vegetação florestal, encontram-se em } \\
\text { processo avançado de regeneração da vegetação arbustiva e/ou arbórea. }\end{array}$ \\
\hline Outros & $\begin{array}{l}\text { Áreas com presença de clareiras e solos expostos; áreas de associação de } \\
\text { diversas modalidades de uso e que devido à resolução espacial das imagens } \\
\text { não é possível uma discriminação dos seus componentes; áreas com padrão } \\
\text { de cobertura diferenciada das demais classes; áreas que tiveram sua } \\
\text { interpretação impossibilitada por nuvens ou sombra de nuvens. }\end{array}$ \\
\hline
\end{tabular}

Fonte: Elaborado pelos autores, 2018.

Para o desenvolvimento do trabalho foi utilizada a base cartográfica em formato vetorial do IBGE. Para produção dos mapas utilizou-se o software ArcGis versão 10.1 (licenciado para o Laboratório de Geoprocessamento da Universidade Federal Rural da Amazônia - Campus Belém).

A produção do mapa de unidades de paisagem da Resex Marinha Mocapajuba teve como base a proposta metodológica de Monteiro (1987), que estabelece o uso das características naturais e de uso e cobertura da Terra para a definição de conjuntos ambientalmente solidários. Sendo assim, buscou-se elaborar um produto partindo do princípio geossistêmico, onde o resultado é a correlação entre os aspectos da sociedade e natureza. A nomenclatura das unidades de paisagem se baseou na classificação taxonômica e os critério tipológicos estabelecidos por Bertrand (2004). 
VALE, J. R. B.; LEITE, T. V. S.; SILVA, E. L. S.; SANTOS, J. F.

Análise espacial das unidades de paisagem da reserva extrativista Marinha Mocapajuba, Zona Costeira do Nordeste Paraense

\section{RESULTADOS E DISCUSSÃO}

Conforme as classificações climáticas de Köppen, o clima predominante na área de estudo é do tipo Am (Clima Tropical de Monção), quente e úmido, com duas estações do ano: uma estação chuvosa (dezembro a maio), e uma estação menos chuvosa, também chamada de estação seca (junho a novembro). De acordo com dados da Estação Meteorológica de Soure, em 2017 a temperatura média foi de $26,3{ }^{\circ} \mathrm{C}$, máximas de $32,5^{\circ} \mathrm{C}$ e mínimas de $20,9^{\circ} \mathrm{C}$.

A precipitação na zona costeira da Amazônia Brasileira é determinada pela influência de vários sistemas atmosféricos que variam desde a escala convectiva a escala sinótica: Linhas de Instabilidade (LI); Zona de Convergência Intertropical (ZCIT); Ondas de Leste (OL); Sistemas de Brisas (marítima e terrestre), e em períodos intervalares, a região é afetada pelos fenômenos El Niño e La Niña, causando desta forma, modificação no regime de precipitação da mesma (COHEN et al., 1995). Sendo assim, a pluviosidade não apresenta uma distribuição espacial homogênea, no ano de 2017 houve uma precipitação de 2.896,3 mm. A Figura 2 apresenta os dados de precipitação e temperatura para a área de estudo.

Figura 2. Histograma de Precipitação e Temperatura na área da Resex Marinha Mocapajuba

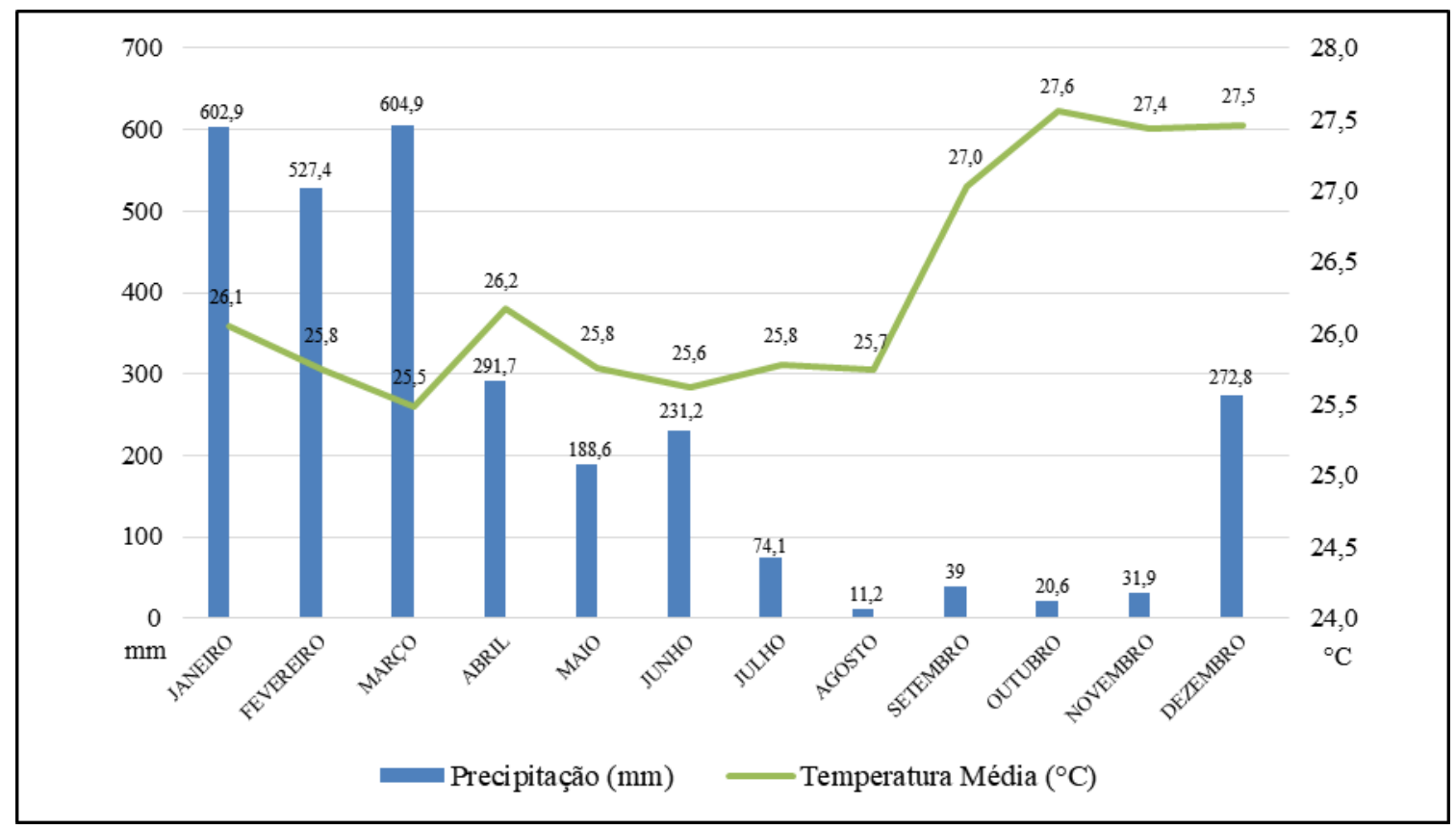

Fonte: INMET (2017). Elaborado pelos autores, 2018. 
VALE, J. R. B.; LEITE, T. V. S.; SILVA, E. L. S.; SANTOS, J. F.

Análise espacial das unidades de paisagem da reserva extrativista Marinha Mocapajuba, Zona Costeira do Nordeste Paraense

Geologicamente a área de estudo (Figura 3) é marcada pela presença de terrenos muito recentes na escala do tempo geológico, depósitos do Período do Terciário (Formação Barreiras) e Quaternário (Pós-Barreiras), mais precisamente, da Época do Holoceno e do Pleistoceno (ROSSETTI et al., 1989). O Holoceno é caracterizado principalmente pelos depósitos de pântanos e mangues, constituídos por sedimentos predominantemente argilosiltosos, com muita matéria orgânica, em ambiente flúvio-marinho e/ou litorâneo. O Pleistoceno é caracterizado por uma cobertura detrito-laterítica com sedimentos argiloarenosos amarelados, gerados por processos alúvio coluviais (ICMBIO, 2014).

Figura 3. Formação Geológica da Resex Marinha Mocapajuba

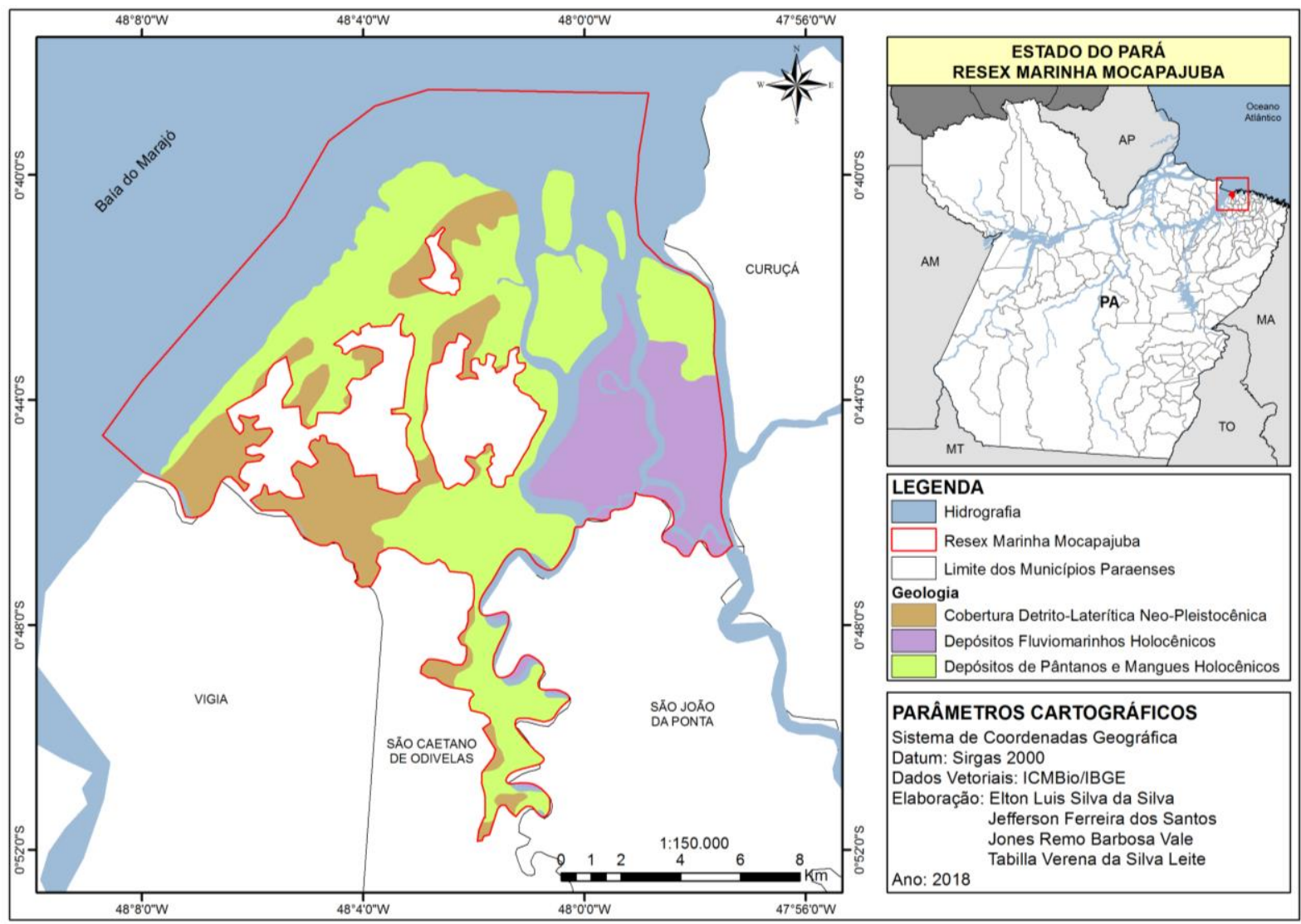

Fonte: Elaborado pelos autores, 2018.

Os sedimentos do Terciário, da Formação Barreiras, se assentam sobre a Formação Pirabas e são sobrepostos pelos sedimentos Pós-Barreiras. Esta unidade é representada na forma de inúmeras falésias e relevo colinoso comuns na área de idade 
VALE, J. R. B.; LEITE, T. V. S.; SILVA, E. L. S.; SANTOS, J. F.

Análise espacial das unidades de paisagem da reserva extrativista Marinha Mocapajuba, Zona Costeira do Nordeste Paraense

Mioceno Inferior (ARAI et al., 1994). Rossetti et al. (1989), colocam que a Formação Barreiras, é constituída por conglomerados polimíticos intercalados por areia e argila.

Sá (1969) destaca que os sedimentos Pós-Barreiras são separados da Formação Barreiras por uma discordância erosiva. Apesar de diversos autores os atribuírem a idade pleistocênica, Rossetti et al. (1989), admitem uma idade holocênica. Esta unidade é constituída por sedimentos areno-argilosos depositados após um período sem deposição.

A geomorfologia da área de estudo encontra-se compartimentada em duas classes: Planícies e Tabuleiros (Figura 4). A Planície, uma área plana resultante da combinação de processos de acumulação fluvial e marinha, sujeita ou não a inundações periódicas, podendo comportar canais fluviais, manguezais, cordões arenosos e lagunas. Os Tabuleiros apresentam formas de relevo de topos tabulares, baixos platôs, com rampas suavemente inclinadas.

Essa região costeira é influenciada por regimes de macromarés $(>4 \mathrm{~m})$, onde predominam feições geomorfológicas características, por exemplo, extensos depósitos de lama de planície de maré, estuários, baixios, pântanos salinos, dunas, praias e leques de lavagens associados (EL-ROBRINI et al., 1992; SOUZA FILHO et al., 1996). 
VALE, J. R. B.; LEITE, T. V. S.; SILVA, E. L. S.; SANTOS, J. F.

Análise espacial das unidades de paisagem da reserva extrativista Marinha Mocapajuba, Zona Costeira do Nordeste Paraense

Figura 4. Estrutura Geomorfológica da Resex Marinha Mocapajuba

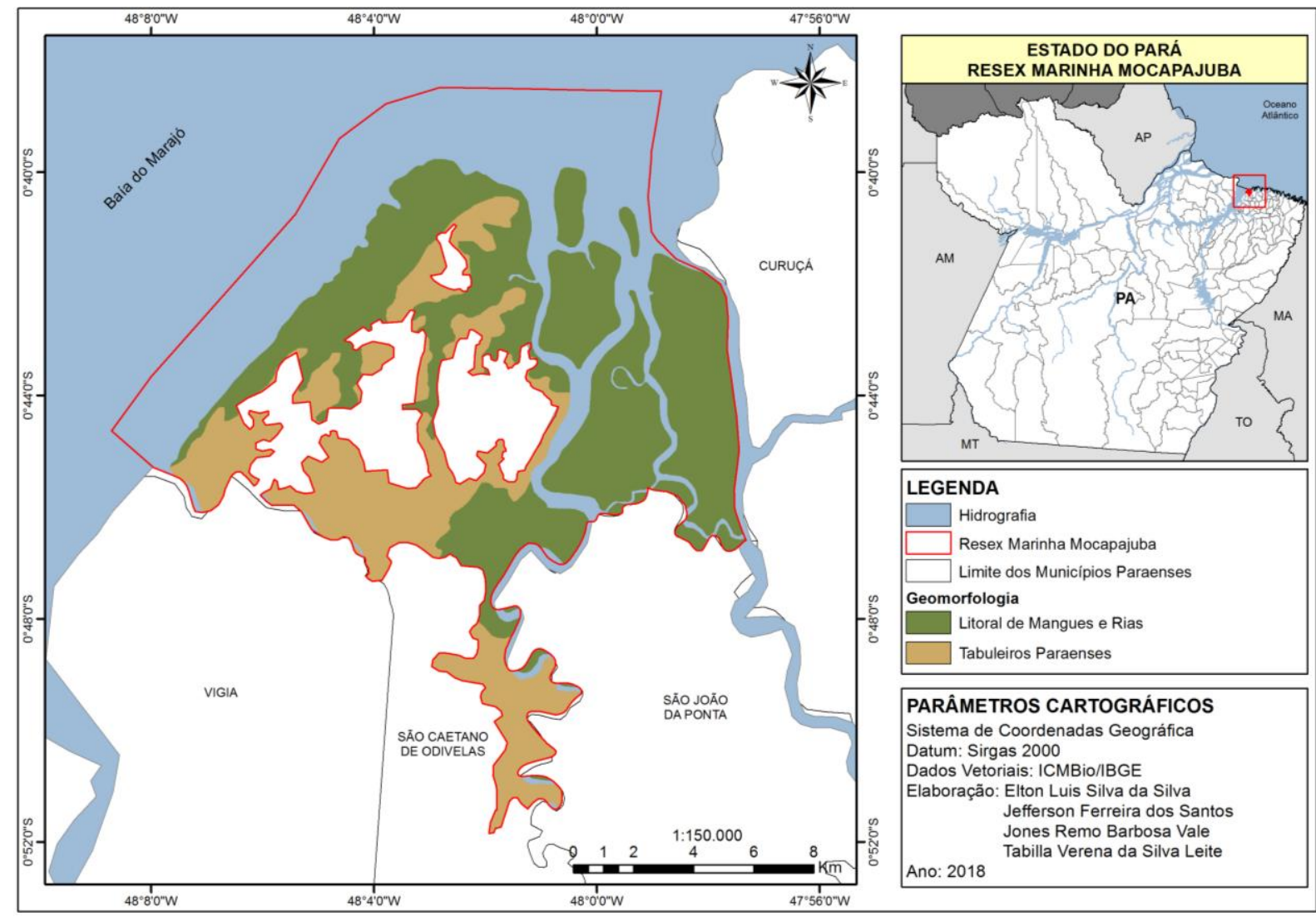

Fonte: Elaborado pelos autores, 2018.

Segundo Carvalho (2007), a zona costeira do nordeste paraense é do tipo estuarino, com a linha de costa recortada por amplas reentrâncias ou "rias" e com cobertura interna, caracterizada por um manto de faixas arenosas. As principais características dessas "rias" são vales fluviais, que cobrem a costa e são parciais ou totalmente invadidos pelo mar. Para El-Robrini et al. (1992), as "rias" adentram até $45 \mathrm{~km}$ no continente, apresentando larguras, de até $20 \mathrm{~km}$ e profundidades inferiores a 5m. Conforme Santos (1996), o "Litoral de Rias" pode-se enquadrar às planícies litorânea e fluvial, formadas sobre sedimentos holocênicos, agrupando praias e dunas.

A área de planície corresponde a uma faixa de terra de largura viável que se estende do limite continental dos depósitos quaternários costeiros, normalmente marcados por uma variação topográfica, até a linha de maré baixa, dentre seus ambientes constituintes destacam-se as planícies de maré, manguezais e praia. Os Tabuleiros são constituídos por pequenos platôs, limitadas por pequenas escarpas com alto grau de aplainamento por intemperismo, formadas pelo grupo Barreira. 
VALE, J. R. B.; LEITE, T. V. S.; SILVA, E. L. S.; SANTOS, J. F.

Análise espacial das unidades de paisagem da reserva extrativista Marinha Mocapajuba, Zona Costeira do Nordeste Paraense

A declividade é considerada como a representação do relevo, isto é, a diferença de altitude entre o ponto mais alto e o mais baixo. Segundo Florenzano (2008), a declividade pode ser expressa em graus ou em porcentagem. A Figura 5 apresenta o mapa de declividade com base nos intervalos sugeridos pela Embrapa (1979), deste modo, classifica-se que a Resex tem relevo plano (0-3\%) e suave ondulado (3-8\%).

$\mathrm{Na}$ Resex encontram-se três tipos de solo (Figura 6), são eles: Espodossolo Ferrihumilúvico Hidromórfico, Gleissolo Sálico Sódico e Latossolo Amarelo Distrófico.

Os Espodossolos são solos, em geral, moderada a fortemente ácidos. São originários, principalmente, de materiais arenoquartzosos, sob condições de clima tropical e subtropical, em relevo plano a ondulado. Ocorrem em locais de umidade elevada, em áreas de surgente, abaciamentos e depressões. Não apresentam aptidão agrícola, sendo indicados para áreas de conservação (ICMBIO, 2014).

Figura 5. Declividade da Resex Marinha Mocapajuba

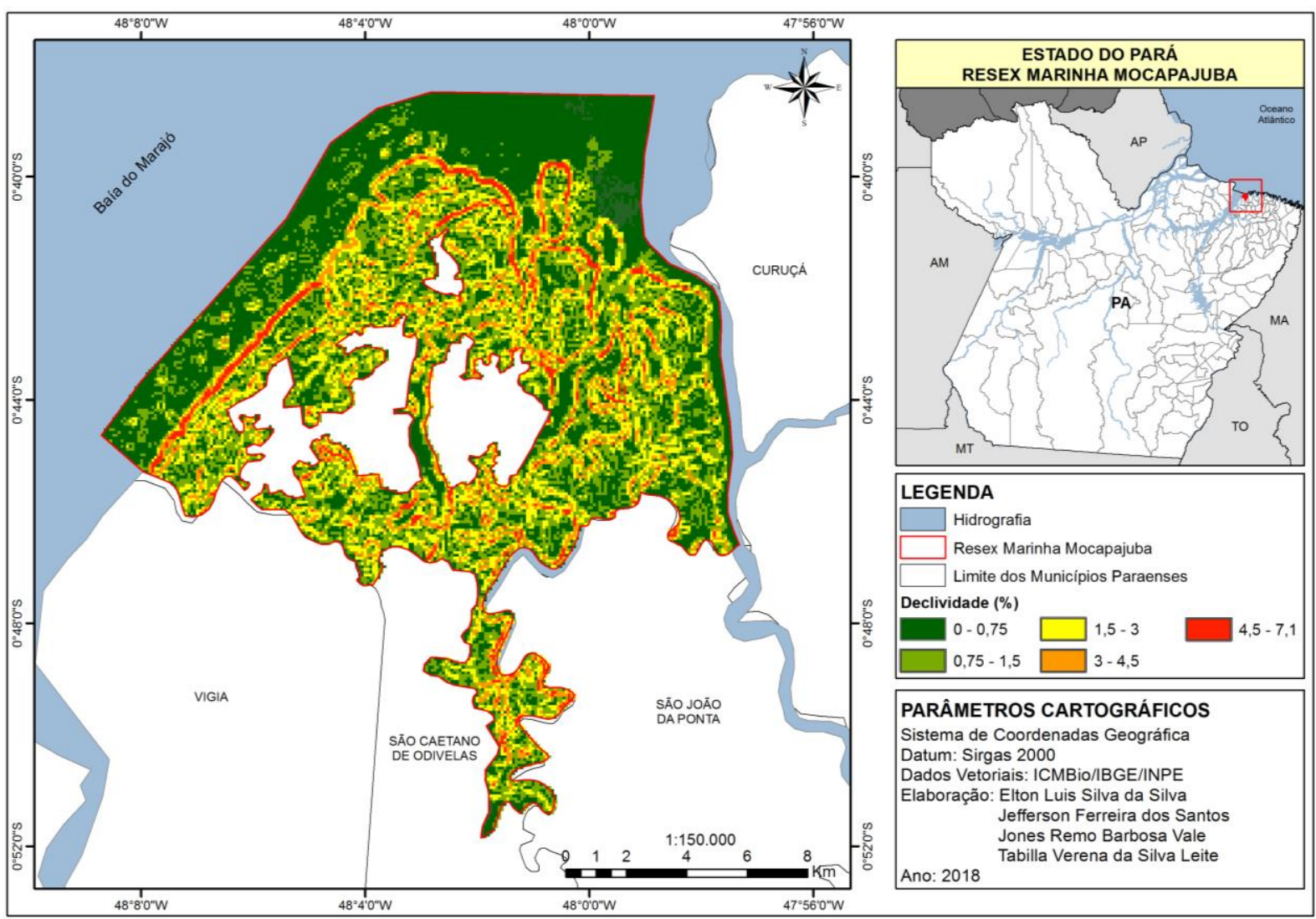

Fonte: Elaborado pelos autores, 2018. 
VALE, J. R. B.; LEITE, T. V. S.; SILVA, E. L. S.; SANTOS, J. F.

Análise espacial das unidades de paisagem da reserva extrativista Marinha Mocapajuba, Zona Costeira do Nordeste Paraense

Os Gleissolos encontram-se permanente ou periodicamente saturados por água, salvo se artificialmente drenados. São comumente desenvolvem-se em sedimentos recentes nas proximidades dos cursos d'água e em materiais colúvio-aluviais sujeitos a condições de hidromorfia (ambientes de influência de água), podendo formar-se também em áreas de terraços fluviais, lacustres ou marinhos (ICMBIO, 2014).

Os Latossolos são solos de intemperização intensa, desenvolvidos de materiais areno-argilosos da formação Barreiras, apresentam normalmente baixa fertilidade, exceto quando originados de rochas ricas em minerais, acidez e alumínio elevado. Possuem boas condições físicas para o uso agrícola, associadas a uma boa permeabilidade (ICMBIO, 2014).

Figura 6. Tipos de solos da Resex Marinha Mocapajuba

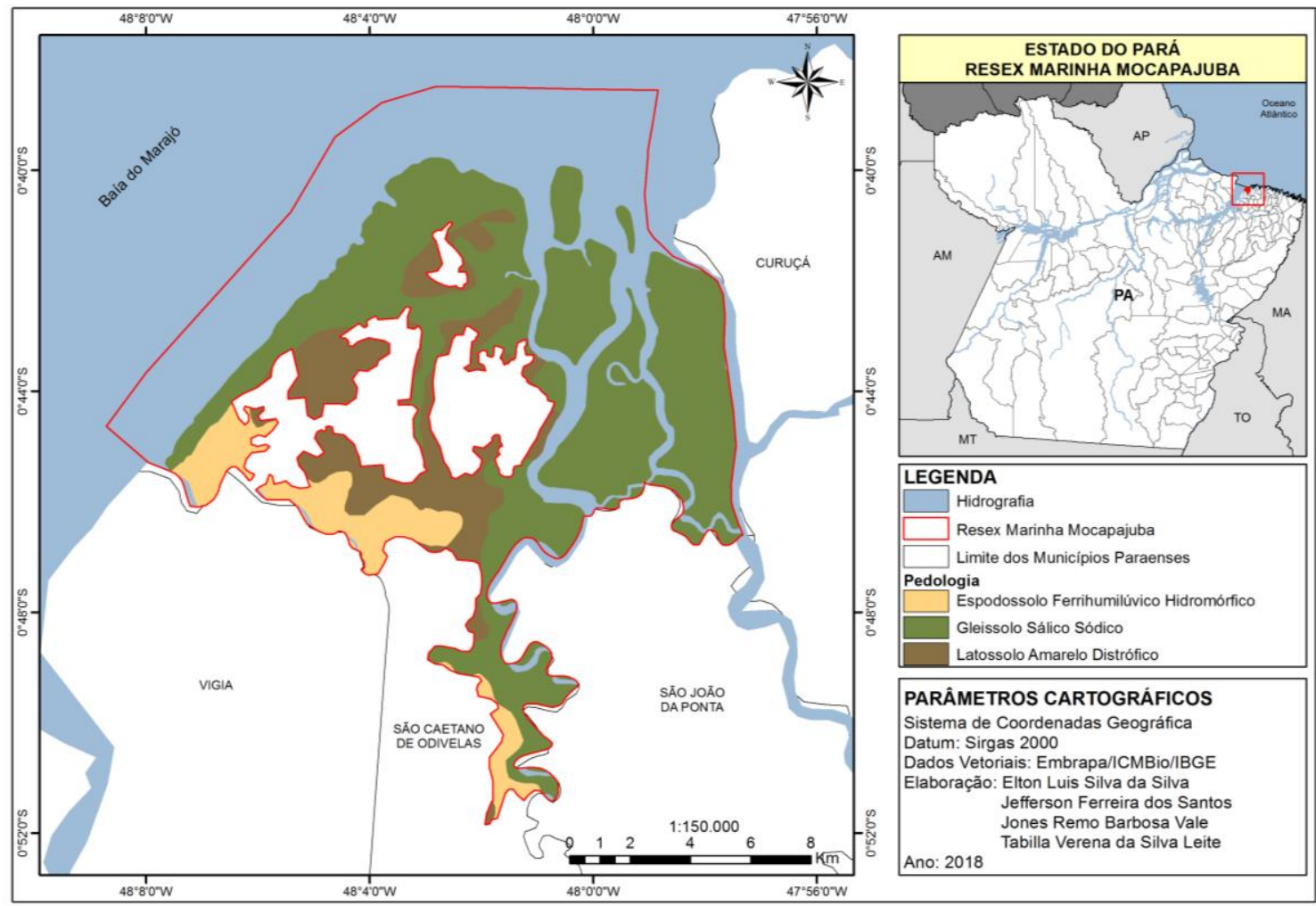

Fonte: Elaborado pelos autores, 2018.

A vegetação encontrada na área de estudo é basicamente formada por manguezais, constituídos por sedimentos lamosos oriundos de depósitos holocênicos. No ambiente, há o predomínio de vegetação hálofila, com espécies do tipo Rhizophora mangle, Avicenia germinans e Laguncularia racemosa. Os manguezais encontram-se em bom estado de 
VALE, J. R. B.; LEITE, T. V. S.; SILVA, E. L. S.; SANTOS, J. F.

Análise espacial das unidades de paisagem da reserva extrativista Marinha Mocapajuba, Zona Costeira do Nordeste Paraense

conservação estando distribuídos ao longo da planície flúvio-marinha, pelas margens das desembocaduras dos rios e as reentrâncias costeiras.

Nos ambientes de transição entre os terrenos de marinha e a terra firme encontram-se áreas de fragmentos de vegetação natural, com presença de vegetação secundária, principalmente, as capoeiras. Essas áreas são resultados do processo de ocupação das comunidades, abertura de áreas para cultivos agrícolas de subsistência e pastagem. Quando a capoeira já está em um estágio avançado, recebe o nome de capoeirão, segundo Teles e Pimentel (2015) esse tipo de vegetação torna-se muito importante para a população local, pois abriga animais de pequeno porte e fornece madeira para uso antrópico. A Figura 7 apresenta os dados do mapeamento do uso e cobertura da Terra da área de estudo.

Figura 7. Uso e cobertura da Terra da Resex Marinha Mocapajuba

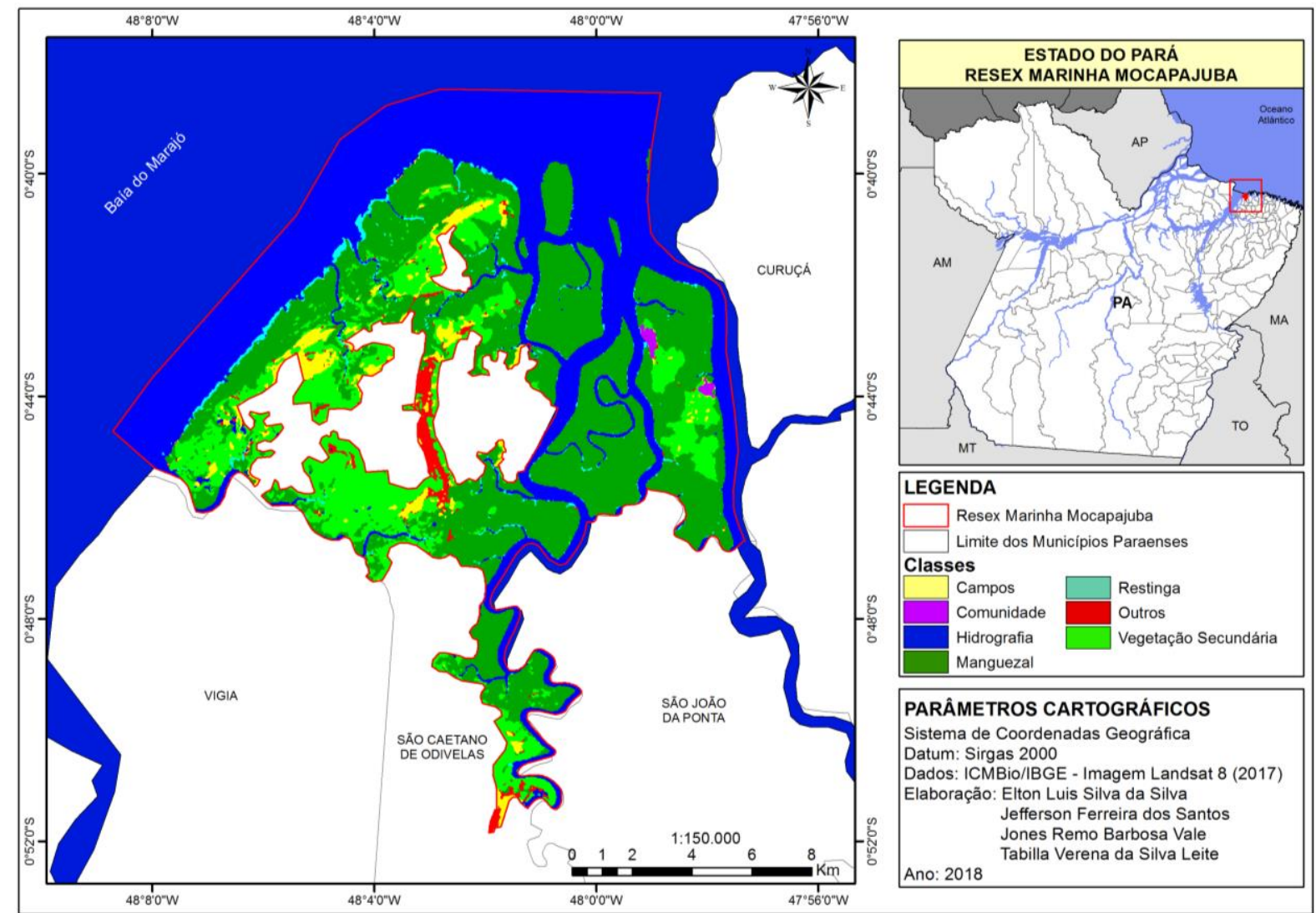

Fonte: Elaborado pelos autores, 2018.

A Zona de Amortecimento de uma UC foi instituída pelo artigo $2^{\circ}$, inciso XVIII do SNUC, que a define como "entorno de uma unidade de conservação, onde as atividades 
VALE, J. R. B.; LEITE, T. V. S.; SILVA, E. L. S.; SANTOS, J. F.

Análise espacial das unidades de paisagem da reserva extrativista Marinha Mocapajuba, Zona Costeira do Nordeste Paraense

humanas estão sujeitas a normas e restrições específicas, com o propósito de minimizar os impactos negativos sobre a unidade". Essas zonas não fazem parte das UC's, mas, localizadas no seu entorno, têm a função de proteger sua periferia, ao criar uma área protetiva que não só as defende das atividades humanas, como também previnem do efeito de borda.

Diante da necessidade de proteger as zonas limítrofes da unidade, foram estabelecidas que a zona de amortecimento fosse composta por áreas continentais e ambientes aquático-marinhos, incluindo áreas que influenciam diretamente a qualidade e a resiliência ecológica da Resex. Sendo assim, a zona de amortecimento tem um raio de $2 \mathrm{~km}$ dos limites territoriais da unidade, tendo uma área de $223,90 \mathrm{~km}^{2}$.

A partir da análise das principais características da paisagem da área de estudo, foi possível identificar as unidades de paisagem (Figura 8 e Quadro 2) que tiveram por critérios o uso da terra, as características da vegetação e os recursos naturais conforme a proposta de Monteiro (1987). A taxonomia adotada é estabelecida por Bertrand (2004).

Figura 8. Unidades de Paisagem e a Zona de Amortecimento da Resex Marinha Mocapajuba

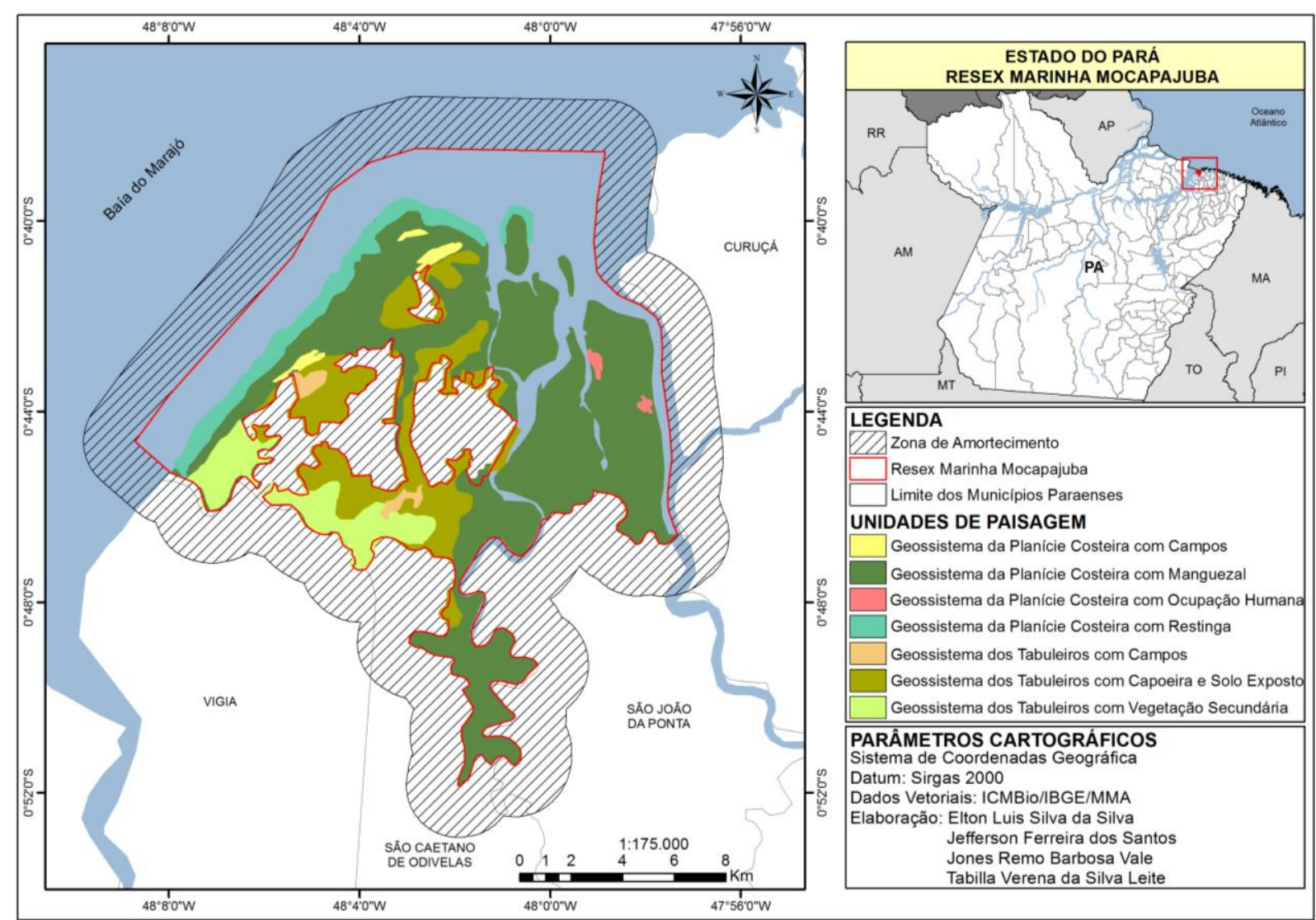

Fonte: Elaborado pelos autores, 2018.

Revista Cerrados, Montes Claros/MG, v. 16, n. 2, p. 153-173, jul./dez.-2018. 
VALE, J. R. B.; LEITE, T. V. S.; SILVA, E. L. S.; SANTOS, J. F.

Análise espacial das unidades de paisagem da reserva extrativista Marinha Mocapajuba, Zona Costeira do Nordeste Paraense

Quadro 2. Características das Unidades de Paisagem da Resex Marinha Mocapajuba

\begin{tabular}{|c|c|c|c|c|c|}
\hline $\begin{array}{c}\text { Unidades de } \\
\text { Paisagem }\end{array}$ & Geologia & Geomorfologia & Declividade & Solos & $\begin{array}{c}\text { Uso } \\
\text { Predominante }\end{array}$ \\
\hline $\begin{array}{c}\text { Geossistema da } \\
\text { Planície Costeira } \\
\text { com Campos }\end{array}$ & Pós-Barreiras & $\begin{array}{c}\text { Litoral de } \\
\text { Mangues e Rias }\end{array}$ & Plano & $\begin{array}{c}\text { Gleissolo } \\
\text { Sálico Sódico }\end{array}$ & Campos \\
\hline $\begin{array}{l}\text { Geossistema da } \\
\text { Planície Costeira } \\
\text { com Manguezal }\end{array}$ & Pós-Barreiras & $\begin{array}{c}\text { Litoral de } \\
\text { Mangues e Rias }\end{array}$ & Plano & $\begin{array}{c}\text { Gleissolo } \\
\text { Sálico Sódico }\end{array}$ & Manguezal \\
\hline $\begin{array}{c}\text { Geossistema da } \\
\text { Planície Costeira } \\
\text { com Ocupação } \\
\text { Humana }\end{array}$ & Pós-Barreiras & $\begin{array}{c}\text { Litoral de } \\
\text { Mangues e Rias }\end{array}$ & Plano & $\begin{array}{c}\text { Gleissolo } \\
\text { Sálico Sódico }\end{array}$ & $\begin{array}{l}\text { Ocupação } \\
\text { Humana }\end{array}$ \\
\hline $\begin{array}{c}\text { Geossistema da } \\
\text { Planície Costeira } \\
\text { com Restinga }\end{array}$ & Pós-Barreiras & $\begin{array}{c}\text { Litoral de } \\
\text { Mangues e Rias }\end{array}$ & Plano & $\begin{array}{c}\text { Gleissolo } \\
\text { Sálico Sódico }\end{array}$ & Restinga \\
\hline $\begin{array}{l}\text { Geossistema dos } \\
\text { Tabuleiros com } \\
\text { Campos }\end{array}$ & Barreiras & Tabuleiros & Plano & $\begin{array}{l}\text { Latossolo } \\
\text { Amarelo } \\
\text { Distrófico }\end{array}$ & Campos \\
\hline $\begin{array}{c}\text { Geossistema dos } \\
\text { Tabuleiros com } \\
\text { Capoeira e Solo } \\
\text { Exposto }\end{array}$ & Barreiras & Tabuleiros & $\begin{array}{c}\text { Suave } \\
\text { Ondulado }\end{array}$ & $\begin{array}{l}\text { Latossolo } \\
\text { Amarelo } \\
\text { Distrófico }\end{array}$ & Outros \\
\hline $\begin{array}{c}\text { Geossistema dos } \\
\text { Tabuleiros com } \\
\text { Vegetação } \\
\text { Secundária }\end{array}$ & Pós-Barreiras & Tabuleiros & $\begin{array}{c}\text { Suave } \\
\text { Ondulado }\end{array}$ & $\begin{array}{c}\text { Espodossolo } \\
\text { Ferrihumilúvico } \\
\text { Hidromórfico }\end{array}$ & $\begin{array}{l}\text { Vegetação } \\
\text { Secundária }\end{array}$ \\
\hline
\end{tabular}

Fonte: Elaborado pelos autores, 2018.

A vegetação costeira se apresenta como fator de síntese da atuação de tais processos, pois, a mesma é altamente especializada, isto é, adaptada a toda essa dinâmica natural, ecológica e antrópica. O manguezal se apresenta como a maior unidade de paisagem da área de estudo. Pela análise espacial o mangue apresenta relação com todas as unidades na sua maior parte de conectividade e de adjacência, deste modo, esta unidade se configura como 
VALE, J. R. B.; LEITE, T. V. S.; SILVA, E. L. S.; SANTOS, J. F.

Análise espacial das unidades de paisagem da reserva extrativista Marinha Mocapajuba, Zona Costeira do Nordeste Paraense

uma das mais importantes do ponto de vista de fluxo gênico e energia da área estudo. Além disso, o mangue é uma grande fonte de recurso para sobrevivência de muitas comunidades locais.

\section{CONSIDERAÇÕES FINAIS}

Analisar as transformações da paisagem geradas pelas ações antrópicas, por meio do uso e ocupação do solo, são fundamentais para o entendimento da dinâmica dos processos dentro de um sistema, uma vez que modifica o fluxo de matéria e energia anterior dando nova dinamicidade ao mesmo. Desta forma, a metodologia adotada na pesquisa se mostrou satisfatória para compreender esses processos. Assim, a delimitação das unidades de paisagem foi importante para elaboração da cartografia da integração das características da unidade como subsídio ao ordenamento territorial.

A identificação das unidades de paisagem da Resex Marinha Mocapajuba através do mapeamento mostrou-se um importante instrumento para subsidiar a elaboração de um plano de manejo de forma que todos os elementos naturais e antrópicos sejam abordados de forma integrada. É importante ressaltar que a Resex ainda não possui um plano de manejo, o plano é um dos principais instrumentos de gestão, nele se estabelece o zoneamento e as normas que devem presidir o uso da área e o manejo dos recursos naturais.

A elaboração do plano de manejo da unidade deve levar em consideração não só as características ambientais, mas também importância dos ecossistemas presentes na unidade para toda a sociedade, de modo, que vise à busca integrada por conservação e ao mesmo tempo a utilização dos recursos naturais. Para isso é necessário uma relação harmônica entre todos os usuários da unidade.

\section{REFERÊNCIAS}

AMORIM, R. R.; OLIVEIRA, R. C. As unidades de paisagem como uma categoria de análise geográfica: o exemplo do município de São Vicente-SP. Sociedade \& Natureza, v. 20, n. 02, p. 177-198, 2008.

ARAI, M.; TRUCKENBRODT, W; NOGUEIRA A. C. R.; GOES, A. M. ROSSETI, D. F. Novos dados sobre a estratigrafia e ambiente deposicional dos sedimentos Barreiras, NE do 
VALE, J. R. B.; LEITE, T. V. S.; SILVA, E. L. S.; SANTOS, J. F.

Análise espacial das unidades de paisagem da reserva extrativista Marinha Mocapajuba, Zona Costeira do Nordeste Paraense

Pará. In: SIMPOSIO DE GEOLOGIA DA AMAZONIA, 4., Belém. Anais... Belém: SBG, 1994. p. 185-187.

BARROS, D. M. Experiências em rios e mangues: lugar, paisagem, e percepção ambiental dos usuários da Reserva Extrativista Marinha de Mocapajuba (PA). 2017. 121f. Dissertação (Mestrado em Geografia) - Universidade Federal do Pará, Belém, 2017.

BENSUSAN, N. Conservação da biodiversidade em áreas protegidas. Rio de Janeiro: FGV, 2006.

BERTRAND, G. Paisagem e Geografia Física Global: esboço metodológico. RA’'E GA, n. 08, p. 141-152, 2004.

BRASIL. Casa Civil. Lei n⿳ 9.985, de 18 de julho de 2000. Sistema Nacional de Unidades de Conservação da Natureza. Brasília, 2000.

. Casa Civil. Decreto de 10 de outubro de 2014. Criação da Reserva Extrativista Marinha Mocapajuba. Brasília, 2014.

Ministério do Meio Ambiente. Áreas Protegidas: Unidades de Conservação/Plano de Manejo. Disponível em: <http://www.mma.gov.br/areas-protegidas/unidades-deconservacao/plano-de-manejo>. Acesso em 20 Ago. 2018.

BREIMAN, L. Random Forests. Machine Learning, v. 45, p. 05-32, 2001. CARVALHO, C. A. Estudo morfoestratigráfico e sedimentológico dos depósitos holocênicos da planície costeira de Maracanã - NE do Pará. 2007. 129f. Dissertação (Mestrado em Geologia e Geoquímica) - Universidade Federal do Pará, Belém, 2007.

CLEMENTE, C. M. S.; SANTOS, P. S. Geotecnologias como suporte para análise da vegetação natural na sub-bacia hidrográfica do Rio Gavião (1988 a 2015). Revista Cerrados, Montes Claros/MG, v.15, n. 01, p. 98-113, 2017.

COHEN, J. C. P.; DIAS, M. A. F. S.; NOBRE, C. A. Environmental conditions associated with Amazonian squall lines: a case studey. Monthly Weather Review, v. 123, n. 11, p. 3163-3174, 1995.

COSTA, S. S. M. Caracterização ambiental da Reserva Extrativista Chico Mendes (Acre/Brasil): subsídios ao plano de manejo. 2000. 168f. Tese (Doutorado em Ciências) Universidade Federal de São Carlos, São Carlos, 2000.

EL-ROBRINI, M.; FARIAS JÚNIOR, L. E. C.; TORRES, A. M.; SOUZA FILHO, P. W. M.; SILVA, M. S. Deposição e Assoreamento das rias do Nordeste do Estado do Pará/Brasil. In: CONGRESSO BRASILEIRO DE GEOLOGIA, 37., São Paulo, 1992. Anais... São Paulo: CBG, 1992. p. 79-80.

EMBRAPA. Súmula da X reunião Técnica de Levantamento de Solos. Rio de Janeiro: Serviço Nacional de Levantamento e Conservação de Solos, 1979. 
VALE, J. R. B.; LEITE, T. V. S.; SILVA, E. L. S.; SANTOS, J. F.

Análise espacial das unidades de paisagem da reserva extrativista Marinha Mocapajuba, Zona Costeira do Nordeste Paraense

FLORENZANO, T. G. Geomorfologia: conceitos e tecnologias atuais. São Paulo: Oficina de Textos, 2008.

FOLETO, E. M.; ZIANI, P. Zoneamento ambiental e diretrizes para o plano de manejo do Parque do Morro em Santa Maria/RS. Revista do Departamento de Geografia, v. 26, p. 1537, 2013.

ICMBIO. Instituto Chico Mendes de Conservação da Biodiversidade. Estudo socioambiental referente à proposta de criação de Reserva Extrativista Marinha no Município de São Caetano de Odivelas, Estado do Pará. Brasília: ICMBio, 2014.

MARQUES NETO, R. Considerações sobre a paisagem enquanto recurso metodológico para a Geografia Física. Caminhos de Geografia, v. 09, n. 26, p. 243-255, 2008.

MEDEIROS, R. Evolução das tipologias e categorias de áreas protegidas no Brasil. Ambiente \& Sociedade, v. 09, n. 01, p. 41-64, 2006.

MENEZES, D. S.; SIENA, O.; RODRÍGUEZ, T. D. M. Ambientalismo e concepções de RESEX, extrativismo e conhecimento no ICMBio na Amazônia Legal. REAd, v. 17, n. 02, p. 451-479, 2011.

MONTEIRO, C. A. F. Qualidade ambiental: recôncavo e regiões limítrofes. Salvador: CEI, 1987.

ROSS, J. L. S. O registro cartográfico dos fatos geomorfológicos e a questão da taxonomia do relevo. Revista do Departamento de Geografia, n. 06, p. 17-29, 1992.

ROSSETTI, D. F.; TRUCKENBRODT, W.; GOÉS, A. Estudo paleoambiental e estratigráfico dos sedimentos Barreiras e Pós-Barreiras na Região Bragantina, Nordeste do Pará. Boletim do Museu Paraense Emílio Goeldi, v. 01, n. 01, p. 25-74, 1989.

SA, J. H. S. Contribuição a geologia dos sedimentos Terciários e Quaternários da Região Bragantina. Boletim do Instituto de Geologia do Rio de Janeiro, v. 03, p. 21-36, 1969.

SANTOS, V. F. dos. Estratigrafia Holocênica Morfodinâmica Atual da Planície Costeira da Ilha de Algodoal e Marudá. 1996. 138f. Dissertação (Mestrado em Geologia e Geoquímica) - Universidade Federal do Pará, Belém, 1996.

SOUZA FILHO, P. W. M.; EL-ROBRINI, M. Sequências estratigráficas do Holoceno como consequência das variações do nível do mar na Planície Costeira Bragantina. In: SIMPÓSIO DE GEOLOGIA DA AMAZÔNIA, 5., Belém, 1996. Anais... Belém: SGB, 1996. p. 203-206.

TELES, G. C.; PIMENTEL, M. A. S. A nova perspectiva de geossistema, proposta por Bertrand, aplicada a bacia hidrográfica do rio Mocajuba - Nordeste Paraense. Boletim Campineiro de Geografia, v. 05, n. 02, p. 381-399, 2015. 
VALE, J. R. B.; LEITE, T. V. S.; SILVA, E. L. S.; SANTOS, J. F.

Análise espacial das unidades de paisagem da reserva extrativista Marinha Mocapajuba, Zona Costeira do Nordeste Paraense

TRICART, J. Paisagem e Ecologia. Inter-Fácies, escritos e documentos. São José do Rio Preto. IBILCE-UNESP, nº 76, 1982.

TRIGUEIRO, A. Mundo Sustentável: abrindo espaço na mídia para um planeta em transformação. 2 ed. São Paulo: Globo, 2005.

XU, H. Modification of normalised difference water index (NDWI) to enhance open water features in remotely sensed imagery. International Journal of Remote Sensing, v. 27, n. 14, p. 3025-303, 2006.

\section{Autores}

Jones Remo Barbosa Vale - Possui Graduação em Geografia pelo Instituto Federal de Educação, Ciência e Tecnologia do Pará (IFPA) e Mestrado em Geografia da Universidade Federal do Pará (UFPA). Atualmente é Graduando em Engenharia Cartográfica e de Agrimensura pela Universidade Federal Rural da Amazônia (UFRA).

Tabilla Verena da Silva Leite - Possui Graduação e Mestrado em Geografia, ambos cursados na Universidade Federal do Pará (UFPA). Atualmente é Professora na Universidade Federal Rural da Amazônia (UFRA).

Elton Luis Silva da Silva - Atualmente é Graduando em Engenharia Cartográfica e de Agrimensura pela Universidade Federal Rural da Amazônia (UFRA).

Jefferson Ferreira dos Santos - Atualmente é Graduando em Engenharia Cartográfica e de Agrimensura pela Universidade Federal Rural da Amazônia (UFRA).

Artigo recebido em: 07 de outubro de 2018.

Artigo aceito em: 20 de dezembro de 2018.

Artigo publicado em: 21 de dezembro de 2018. 